\title{
USING SOLANUM GLAUCOPHYLLUM AS A SOURCE OF 1,25-DIHYDROXYVITAMIN D TO PREVENT HYPOCALCEMIA IN DAIRY COWS
}

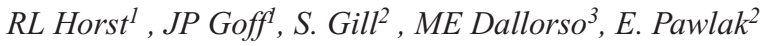 \\ ${ }^{1}$ USDA/ARS, National Animal Disease Center, Ames, IA 50010; ${ }^{2} \mathrm{CAE}$, Buenos Aires, Argentina; \\ ${ }^{3}$ Universidad Nacional de Lomas de Zamora, Buenos Aires, Argentina
}

Reducing cation-anion difference of diets (DCAD) fed just before parturition can prevent milk fever. However this dietary regimen does not entirely eliminate hypocalcemia. Milk fever can also be prevented by exogenous administration of the calcium regulating hormone 1,25-dihydroxyvitamin $\mathrm{D}$. Unfortunately 1,25-dihydroxyvitamin D treatment remains expensive and the pre-partal diets used in most trials would be classified today as high in cations. Solanum glaucophyllum $(\mathrm{Sg})$ is a plant that contains high levels of a glycoside form of 1,25-dihydroxyvitamin D. S. Glaucophyllum is widely distributed in the province of Buenos Aires in Argentina and in Brazil and causes the development of a calcinotic disease in cattle called "Enteque Seco". In order to become active the glycoside must be cleaved to liberate the $1,25(\mathrm{OH})_{2} \mathrm{D}_{3}$. Rumen microbes are very efficient at this process. Could administration of $\mathrm{Sg}$ leaves to cows that were already being fed a low DCAD pre-partum diet further improve calcium status at calving? Nine multiparous Jersey cows were fed a low DCAD diet prior to calving. Urine $\mathrm{pH}$ of cows was maintained below 7.0 in all cows the week prior to parturition. Five cows were daily given 2 or $3 \mathrm{~g} \mathrm{Sg}$ leaves in gelatin boluses beginning 6 days (on average) before calving and continuing for the first 14 days of lactation. None of the four cows fed the low DCAD diet only developed milk fever. Their blood calcium concentration was 7.6, 7.0 and $8.0 \mathrm{mg} / \mathrm{dl}$ the day of calving and $\mathrm{d} 1$ and 2 after calving respectively. Cows receiving Sg in addition to low DCAD diet had significantly higher blood calcium concentration during the periparturient period with blood calcium concentrations of $7.8,8.8$ and $9.3 \mathrm{mg} / \mathrm{dl}$ the day of calving and $\mathrm{d} 1$ and 2 after calving respectively. Defining subclinical hypocalcemia as blood calcium $<7.5 \mathrm{mg} / \mathrm{dl}$, control cows suffered an average of 3 days of subclinical hypocalcemia and the $\mathrm{Sg}$ treated cows suffered $0.8 \mathrm{~d}$ of subclinical hypocalcemia the first $2 \mathrm{wk}$ of lactation. Thus, $\mathrm{Sg}$ treatment improved calcium status in animals that were also being fed a low DCAD diet. Unfortunately, all cows receiving Sg suffered 1-2 days of hypocalcemia (1 cow developed milk fever) between 6 and 8 days after Sg treatment was ended. Mean blood calcium on d 22 of lactation of Sg cows was $6.9 \mathrm{mg} / \mathrm{dl}$ compared with $9.2 \mathrm{mg} / \mathrm{dl}$ in untreated cows. It appears that Sg treatment supplanted the cow's own calcium homeostasis mechanisms so that abrupt withdrawal of treatment left the cows temporarily unable to control blood calcium concentration. Additional experiments were conducted using a phased withdraw approach. Three cows were treated with $\mathrm{Sg}$ from 5 days prepartum to 7 postpartum $(2 \mathrm{~g} \mathrm{Sg} / \mathrm{d})$ from day 8-14 postpartum $(1 \mathrm{~g} \mathrm{Sg} / \mathrm{d})$ and day 15-21 postpartum $(0.5 \mathrm{~g} \mathrm{Sg} / \mathrm{d})$. The phased withdrawal approach resulted in normal calcium concentration for up to 2 weeks following cessation of Sg. These data suggest that $\mathrm{Sg}$ can be used successfully in the prevention of hypocalcemia and that a phased withdrawal approach to removing the exogenous source of $1,25-(\mathrm{OH})_{2} \mathrm{D}_{3}$ was successful in avoiding the hypocalcemic side effects associated with abrupt withdrawal. 